\title{
Factors influencing the outcome of elective paediatric orthopaedic operations in Ile-Ife, Nigeria
}

\author{
A.L. AKINYOOLA*, O.O. ADEGBEHINGBE ${ }^{1}$ and O.J. OGUNDELE ${ }^{2}$ \\ ${ }^{1}$ Department of Orthopaedic Surgery and Traumatology, Obafemi Awolowo University, Ile-Ife, Nigeria; \\ ${ }^{2}$ Department of Orthopaedic Surgery and Traumatology, Obafemi Awolowo University Teaching Hospitals \\ Complex Ile-Ife, Nigeria
}

\begin{abstract}
There is a paucity of published data on the types of paediatric orthopaedic conditions that require surgery and factors influencing their outcome in most parts of Sub-Saharan Africa. This is a necessary audit to improve paediatric orthopaedic practice. We carried out an audit of all elective orthopaedic operations performed in children at Awolowo University Teaching Hospitals Complex in Ile-Ife, Nigeria from January 2000 through December 2005. The aim was to document the clinical outcomes and the factors that influence them. This is with a view to instituting necessary measures to improve paediatric orthopaedic practice in the area. A total of 146 children who had elective operations on 210 limbs were included in the study. Their mean age was 75.6 \pm 66.8 months (range 0.3-396 months). The commonest indications for surgery were angular knee deformities (from Blount's disease and rickets) and club foot. The mean hospital stay before surgery was $12 \pm 8.8$ days (range 1-38days). The mean duration of operation was $78.4 \pm 36 \mathrm{~min}$. (range $30-195 \mathrm{~min}$ ). The total length of hospitalization was $34.97 \pm 19.91$ days in males and $41.97 \pm 25.15$ days in females. Wound infection was the commonest postoperative complication $(8.2 \%)$. The patient's age $(P=0.002)$, indication for surgery $(P=0.008)$, length of preoperative hospital stay $(P=0.048)$, length of operation $(P<0.001)$ and intraoperative blood loss above $200 \mathrm{ml}(P<0.001)$ were found to be statistically significant factors adversely affecting the surgical wound outcome. We conclude that most of the factors that predicted poor outcome in this study were patient and environment-related and are preventable. There is need to upgrade facilities in health institutions in Nigeria.
\end{abstract}

Key words: paediatric, orthopaedic, operations, prognosis, Nigeria

\section{Introduction}

The subspecialty of paediatric orthopaedic surgery is relatively new in most parts of sub-Saharan Africa. There is therefore a paucity of published data on the type of orthopaedic conditions that require surgery among children in our environment. Furthermore in contrast to numerous reports in adults little information is available on postoperative complications and risk factors in paediatric orthopaedic operations (Duque-Estrada et al., 2003; Horwitz et al., 1998; Kaabachi et al., 2005). Operative procedures are the most definitive mode of treatment in paediatric orthopaedics (Staheli, 2006). It is a well known fact that children have greater healing potential and fewer complications than adults, thereby increasing the chance of a successful outcome, all things being equal (Bhattacharyya \& Kosloske, 1990; Staheli, 2006). To avoid complications the risk must be identified preoperatively and preventive measures taken (Staheli, 2006).

The management and outcome of paediatric orthopaedic operations vary considerably between the developed and developing countries (Ekenze et al., 2006). Delay in presentation, shortage of personnel and inadequate facilities are major limitations in the management of children in our environment (Ekenze et al., 2006). All the elective paediatric orthopaedic operations carried out, over a 6-year period, in the department of Orthopaedic Surgery and Traumatology of the Obafemi Awolowo University Teaching Hospitals Complex, Ile-Ife, Nigeria, were studied. The aim of the study was to identify the common indications for elective paediatric orthopaedic operations, postoperative complications and factors contributing to their prevalence. This is with a view to instituting necessary preventive measures.

\section{Materials and Methods}

\section{Study area and patients}

This is a retrospective audit of all elective paediatric orthopaedic operations carried out between January 2000 and December 2005 inclusive. The study setting was the Obafemi Awolowo University Teaching Hospitals Complex, Ile-Ife, Nigeria. The hospital is a 554-bed facility in the south western Nigeria. The biodata of each patient, pre-surgery hospital stay (days), pre-operative haemogram, diagnosis (indication for

* Correspondence: Dr. A.L. Akinyoola; E-mail: aakinyoola@yahoo.co.uk 
surgery), surgical operation performed, duration of operation (minutes), intra operative blood loss and duration of tourniquet application (when used) were recorded. Intravenous cefuroxime (Zinacef by Glazo Limited, UK) was the preoperative antibiotic of choice where indicated. Excluded were patients older than 16years, American Society of Anesthesiology class greater than 2, bone and joint infections, malignancies, open fractures, sickle cell disease (HbSS and $\mathrm{Hb} \mathrm{SC}$ ) patients and patients with HIV/AIDS. All the surgeries were performed by the consultant staff and senior registrars. The operating room environment was similar for all the patients. A surgical wound was expected to heal in each patient within 14 days. A pre-surgical hospital stay beyond 72 hours and a post operative hospital stay beyond 14 days were defined abnormal.

The outcomes that were measured were post-operative complications, the wound status (presence or absence of infection and duration of wound healing), length of post operative hospital stay (days), and microbiology of the surgical wound site (if infected). Wound infection was defined as a purulent discharge from the wound either spontaneously or on removal of sutures. A patient with wound infection, recurrence of deformity or abnormal post operative hospital stay was considered to have unsatisfactory outcome.

\section{Data analysis}

The data were analyzed using the Statistical Package for Social Sciences (SPSS) version 11.0 for win-

\section{Results}

A total of 489 children were admitted and treated for different kinds of elective paediatric orthopaedic disorders during the study period. A total of 146 patients, who had elective orthopaedic operations on $210 \mathrm{limbs}$, constituting $42.9 \%$ of all elective paediatric orthopaedic surgery cases, fulfilled the study inclusion criteria. Sixty three patients (males $=52.1 \%$; females $=47.9 \%$ ) had bilateral pathology, mainly knee deformities (including Blount's disease and rickets) and club foot (Table 1). Congenital limb deformities (absent radius, absent tibia, tibia pseudarthrosis and polydactyl) accounted for $27.6 \%$ of the diagnoses. The mean age was 75.6 \pm 66.8 months (range: 0.3 396 months). Children in the under-five (years) age group constituted $57.5 \%$ of the study population while $82.2 \%$ of the patients were in the first decade of life. Ninety patients $(61.6 \%)$ had bone operations while 56 (38.4\%) had soft tissue surgery (Table 2).

The mean hospital stay before surgery was $12 \pm 8.8$ days (range $1-38$ days, 2 -tailed test $P=0.048$, $\mathrm{CI}=-5.733-0.029)$. The mean total hospital stay for males was $34.97 \pm 19.91$ days and for females was $41.97 \pm 25.15$ days (2-tailed test $P=0.063, \mathrm{CI}=-14.39$ $\pm 0.395)$. The mean packed cell volume PCV) at surgery was $34.7 \pm 3.8 \%$ (range $26-42 \%$ ). A total of 122 patients $(83.6 \%)$ had haemoglobin genotype AA while $24(16.4 \%)$ had AS. The mean duration of surgery was

Table 1: Patients' diagnosis at surgery

\begin{tabular}{lll}
\hline Diagnosis & No. of limbs & $\%$ \\
\hline Angular knee deformities & 120 & 57.1 \\
Club foot & 58 & 27.6 \\
Congenital limb deformities & 16 & 7.6 \\
Post traumatic deformities & 10 & 4.8 \\
Polio deformities & 4 & 1.9 \\
Baker's cyst & 2 & 1.0 \\
\hline \multicolumn{1}{c}{$\quad$ Total } & 210 & 100 \\
\hline
\end{tabular}

dows. Transformation of variables was done where necessary, in particular quantitative variables. Test of significance was calculated by the use of Analysis of Variance (ANOVA), chi-square tests with Fischer's exact test where numbers were small and Yates correction when indicated. Student $t$-test was used to compare the means. Bivariate correlation was carried out to determine the relationship between variables and the correlation between outcome, wound status and other variables using binary logistic regression analysis.
78.4 \pm 36 minutes (range: $30-195$ minutes). The mean duration of tourniquet application (where it was used) was $20.5 \pm 25.7$ minutes (range 15 to 125 minutes).

The surgical wound status, duration of wound healing and determinants of outcome are summarised in Table 3. Wound infection was the commonest post operative complication. The patient's age $\left(\chi^{2}\right.$ $=12.792, \mathrm{df}=2, P=0.002)$, pre-operative diagnosis (indication for surgery) $\left(\chi^{2}=15.701, \mathrm{df}=5, P=0.008\right)$, 
Table 2: Types of surgical operations performed

\begin{tabular}{lcc}
\hline Operation & No of patients & Percentage \\
\hline Corrective osteotomy & 80 & 54.8 \\
Soft tissue release & 44 & 30.1 \\
Open reduction and internal fixation of fractures & 4 & 5.4 \\
Centralization (carpus \& ankle) & 4 & 5.4 \\
Excision (Extra digits, Baker's cyst) & 10 & 13.6 \\
Triple arthrodesis & 4 & 5.4 \\
\hline Total operations & 146 & 100 \\
\hline
\end{tabular}

length of preoperative hospital stay $(P=0.048)$, length of operation $\left(\chi^{2}=42.160, \mathrm{df}=2, P=0.000\right)$ and intra operative blood loss above $200 \mathrm{ml}\left(\chi^{2}=18.667, \mathrm{df}=2\right.$, $P=0.000)$ were found to be statistically significant factors affecting the surgical wound outcome. Gen$\operatorname{der}\left(\chi^{2}=0.625, \mathrm{df}=1, P=0.429\right)$, type of operation performed -bone or soft tissue surgery $\left(\chi^{2}=1-530\right.$, $\mathrm{df}=1, P=0.216)$ and haemoglobin genotype $\left(\chi^{2}=\right.$
( 2 tailed test $+0.568, P=0.000)$. Seventeen $(8.1 \%)$ wounds developed infections (10 superficial $-4.8 \%$, 7 deep - 3.3\%) (Table 4).

When the patients were stratified into age groups, $95.2 \%$ of the patients under the age of 5years had satisfactory outcome. Sixty percent of overall unsatisfactory outcome was accounted for by those in the age group 5-10 years. There was thus a statistically

Table 3: Surgical wound status, duration of wound healing, post-operative complication

\begin{tabular}{lcc}
\hline Clinical outcome & Frequency & Percentage \\
\hline Surgical wound status & 193 & 91.9 \\
No wound infection & 10 & 4.8 \\
Superficial wound infection & 7 & 3.3 \\
Deep wound infection & & 21.9 \\
$\quad$ Duration of wound healing(days) & 46 & 78.1 \\
$\quad$ within 14 days & 164 & 8.1 \\
Post operative complications & & 4.1 \\
Wound infection & 17 & 2.7 \\
Malaria & 6 & 4 \\
Anaemia & 4 & \\
\hline
\end{tabular}

2.112, $\mathrm{df}=1, P=0.146$ ) did not significantly affect the outcome of surgery. There was a positive correlation between age and duration of wound healing ( 2 tailed test, $+0.231, P=0.006$ ). There was also a significant correlation between length of hospital stay before operation and length of post operative hospital stay significant difference in the surgical outcome between the under 5 age group and those between 5 and 10 years $\left(\chi^{2}=12.792, \mathrm{df}=2, P=0.002\right)$. All the 26 patients $(17.8 \%)$ above the age of 10 had satisfactory outcome. There was no significant difference in the outcome of surgery between the age group 10 to 15 years and those under 5 years. The reason for this is not clear

Table 4: Determinants of surgical outcome

\begin{tabular}{lll}
\hline Determinant & Mean & P-value \\
\hline Age(months) & $75.6 \pm 66.8$ & 0.002 \\
Gender & - & 0.429 \\
Haemoglobin genotype & - & 0.146 \\
Indication for surgery(diagnosis) & - & 0.008 \\
Type of operation(bone or soft tissue) & - & 0.216 \\
Preoperative hospitalization(days) & $12 \pm 8.8$ (range 1-38) & 0.048 \\
Duration of surgery(minutes) & $78.4 \pm 36$ (range 30-195) & 0.000 \\
Intraoperative blood loss above 200mls & - & 0.000 \\
\hline
\end{tabular}


from this study.

\section{Discussion}

This audit of elective paediatric orthopaedic operations has revealed some predictors of outcome in IleIfe, Nigeria. There was a positive correction between age and duration of wound healing. Surgical wound infection is a significant source of postoperative morbidity in orthopaedics surgery (Duque-Estrada et al., 2003; Horwitz et al., 1998; Kaabachi et al., 2005). Such infections prolong wound healing and thus the length of hospital stay and overall cost of treatment. The wound site infection rate in our study was higher than that reported for clean paediatric surgery by other workers (Duque-Estrada et al., 2003; Horwitz et al., 1998; Kaabachi et al., 2005) but similar to the rate in a series of paediatric orthopaedic operations (Kaabachi et al., 2005). Further studies are necessary to establish whether surgical site infection rate is higher in clean paediatric orthopaedic operations than in non-orthopaedic paediatric surgery cases.

We found the indication for surgery to be a determinant of postoperative surgical site infection. Patients with club foot and knee deformity (especially Blount's disease) had worse prognosis. Talipes equino varus deformity has been found to be a significant risk factor for postoperative wound infection in a study conducted in Tunisia (Kaabachi et al., 2005).

The length of preoperative hospitalization was a risk factor for surgical site infection in this study. The mean hospital stay before surgery of $12 \pm 8.8$ days was rather too long. This is due to logistic problems like poor power (electricity) supply and inadequate facilities necessitating frequent cancellation of operation lists in most of our hospitals in Nigeria. The length of preoperative hospital stay has been reported to be an important risk factor for surgical site infection in nosocomial infections surveillance in Dutch orthopaedic patients (de Boer et al., 1999). However some studies could not demonstrate any significant association between the length of preoperative hospitalization and wound infection (Duque-Estrada et al., 2003; Horwitz et al., 1998; Bhattacharyya \& Kosloske, 1990). The surgical site infection rates among patients undergoing elective surgery on the same day of their hospitalization was found not to be significantly lower than that of other patients that required preoperative hospitalization (Manian \& Meyer, 1998). Another factor that significantly correlated with poor wound status was the length of operation. The longer the operation time the worse the wound status. Increasing duration of operation more than 1hour has been generally found to increase the rate of surgical site infection in most studies (Duque-Estrada et al., 2003; Horwitz et al., 1998; Kaabachi et al., 2005; Bhattacharyya \& Kosloske, 1990; Al-Habdan \& Sadat-Ali, 2003; Uludag et al., 2000). This is due to higher chance of wound contamination, especially from glove perforation (Al-Habdan et al., 2003). The amount of intra operative blood loss, especially if more than $200 \mathrm{ml}$, also significantly affected the outcome of surgery. This, if not replaced adequately, may lead to postoperative anaemia $(2.7 \%$ in this study). This delays wound healing and thus the outcome.

This study has shown that most of the factors that predict poor outcome by increasing the rate of surgical site infection and prolonging the post operative hospitalization are related to both the patient and the environment. The length of pre-operative hospitalization should be shortened because it increases the rate of surgical site infection and overall cost of treatment. Infrastructural facilities in hospitals in Nigeria should be upgraded. More paediatric orthopaedic surgeons need to be trained. All these would shorten the waiting time before patients have their operations. Paediatric orthopaedic practice, being relatively new in most parts of Africa, is a fertile and very challenging subspecialty of orthopaedic surgery. There is need for more prospective studies to highlight these challenges with a view to improving the outcome of paediatric orthopaedic operations.

Received 18 January 2008

Revised 25 March 2008

Accepted 26 March 2008

\section{References}

Al-Habdan, I. \& Sadat-Ali, M. (2003) Glove perforation in pediatric orthopaedic practice. Journal of Pediatric Orthopaedics 23, 791-793.

Bhattacharyya, N. \& Kosloske, A.M. (1990) Postoperative wound infection in paediatric surgical patients: a study of 676 infants and children. Journal of Pediatric Surgery 25,125-129.

de Boer, A.S., Mintjes-de Groot, A.J., Severijnen, A.J., van den Berg, J.M. \& van Pelt, W. (1999) Risk assessment for surgical - site infections in orthopaedic patients. Infection Control and Hospital Epidemiology 20, 402-407.

Duque-Estrada, E.O., Duarte, M.R., Rodrigues, D.M. \& Raphael, M.D. (2003) Wound infection in paediatric surgery: a study of 575 patients in a university hospital. Pediatric Surgery International 19, 436-8

Ekenze, S.O., Ikechukwu, R.N. \& Oparaocha, D.C. 
(2006) Surgically correctable congenital anomalies; prospective analysis of management problems and outcome in a developing country. Journal of Tropical Pediatrics 52, 126-131.

Horwitz, J.R., Chwals, W.J., Doski, J.J., Suescum, E.A., Cheu, H.W. \& Lally, K.P. (1998) Paediatric wound Infections: a prospective multicenter study. Annals of Surgery 227, 553-558

Kaabachi, O., Letaief, I., Nessib, M.N., Jelel, C., Ben Abdelaziz, A. \& Ben Ghachem, M. (2005) Prevalence and risk factors for postoperative infection in pediatric orthopaedic surgery: a study of 458 children. Revue de Chirurgie
Orthopedique et Reparatrice de l'Appareil Moteur 91,103-108.

Manian, F.A. \& Meyer, L. (1998) Surgical site infection rates in patients who undergo elective surgery on the same day as their hospital admission. Infection Control and Hospital Epidemiology 19, 17-22

Staheli, L.T. (2006) Practice of Pediatric Orthopaedics, $2^{\text {nd }}$ Edition. Lippincott Williams and Wilkins, Philadelphia. pg 48

Uludag, O., Rieu, P., Niessen, M. \& Voss, A. (2000) Incidence of surgical site infection in pediatric patients: a 3-month prospective study in an academic Pediatric Surgical Unit. Pediatric Surgery International 16, 417-420. 